\title{
Perfusion CT evaluation in experimentally induced testicular torsion
}

\author{
Gulgun Yilmaz Ovali, MD; ${ }^{*}$ Omer Yilmaz, MD; ${ }^{\dagger}$ Serdar Tarhan, MD; ${ }^{*}$ Abdulkadir Genc, MD; ${ }^{\dagger}$ Peyker Demireli, MD; ${ }^{\xi}$ \\ Ozum Tunçyurek, MD; ${ }^{*}$ Cansu Unden, MD; ${ }^{\dagger}$ Can Taneli, MD; ${ }^{\dagger}$ Yüksel Pabuscu, MD*
}

See related article on page 387

\section{Abstract}

Infroduction: In this study, we define the characteristics of perfusion computed tomography (CT) in an experimental model of testicular torsion.

Methods: Twenty male Sprague-Dawley rats were included for the study. Torsion was applied to 10 rats and perfusion CT was performed in the first hour to evaluate the following perfusion parameters: blood flow (BF), blood volume (BV) and time to peak (TTP) values. Detorsion was done for the same rats, and perfusion CT was repeated 2 hours later to evaluate reperfusion. Ten rats were left as part of the control group.

Results: There is significant statistical correlation between the BF and $\mathrm{BV}$ values in the torsion and control groups $(p=0.001$ and $p=0.001$, respectively). There is no statistical correlation of the TTP parameters between the groups. No correlation was found between torsion and detorsion perfusion parameters.

Conclusion: Perfusion CT can demonstrate the testicular perfusion insult in an experimental model of torsion. Perfusion CT may be an alternative method for diagnosis of torsion in indeterminate cases. Following detorsion an interval of 2 hours is not sufficient for demonstrating luxury perfusion of the testis.

Can Urol Assoc J 2009;3(5):383-6

\section{Résumé}

Introduction : Dans cette étude, nous définissons les caractéristiques d'une tomodensitométrie (TDM) de perfusion dans un modèle expérimental de torsion testiculaire.

Méthodologie : Vingt rats Sprague-Dawley mâles ont été utilisés pour l'étude. Une torsion a été appliquée chez 10 rats et une TDM de perfusion a été effectuée dans I'heure suivante pour évaluer les paramètres suivants : débit sanguin (DS), volume sanguin (VS) et temps nécessaire pour arriver aux valeurs maximales (TVM). On a procédé à une détorsion chez les mêmes rats avant de répéter la TDM de perfusion 2 heures plus tard. Les 10 autres rats formaient le groupe témoin.

Résultats : Il existe une corrélation significative sur le plan statistique entre les valeurs de DS et de VS dans le groupe ayant subi la torsion et le groupe témoin ( $p=0,001$ et $p=0,001$, respectivement). Par contre, aucune corrélation statistique n'a été observée dans les deux groupes concernant les valeurs de TVM, ni entre les paramètres de perfusion liés à la torsion et la détorsion.
Conclusion : Une TDM de perfusion peut permettre de démontrer une anomalie de perfusion testiculaire selon un modèle expérimental de torsion. La TDM de perfusion peut constituer une méthode diagnostique de rechange dans les cas indéterminés. Après la détorsion, un intervalle de 2 heures ne suffit pas pour démontrer une perfusion excessive des testicules.

\section{Introduction}

Testicular torsion is a urologic emergency and must be differentiated from other complaints of testicular pain; a delay in diagnosis can lead to loss of the testicle. ${ }^{1}$ Testicular torsion tends to peak twice in one's lifetime: in newborn and adolescence periods. More than half of the cases are patients under the age of $21 .^{2}$ In adolescent males, testicular torsion is the most frequent cause of testicle loss. ${ }^{3}$ Highresolution ultrasound (US) with colour-flow Doppler and radionuclide imaging are 2 techniques that can provide information about testicular blood flow (BF). ${ }^{4}$

Perfusion CT is an investigative tool adding functional value to the CT examination. Perfusion, which is one of the functional evaluation parameters, is a basic physiological quantity that includes diagnostic information of the abnormal tissue. Perfusion is the amount of blood that passes through each unit volume of a tissue. As the metabolic needs of the tissues are supplied through perfusion, perfusion CT examination is the indirect criterion of the tissue's metabolic activity. The following parameters can be measured by perfusion CT examination: BF speed in unit time, total blood volume (BV) that passes through unit tissue and average passing time. Perfusion CT is a method that can be incorporated into conventional CT systems, thereby broadening the technique's availability. ${ }^{5,6}$

Standard diagnostic methods for testicular torsion (i.e., Doppler US and radionuclide scanning) remain unresolved and insufficient in some cases, according to the literature. ${ }^{4}$ In such indeterminate situations, the cases are directed immediately to surgery. In this study, we investigate the efficiency of perfusion CT scan. Our results show that a perfusion CT scan is effective in tissue perfusion in an experimental testicular torsion model to avoid unnecessary surgery. 
Ovali et al.

\section{Methods}

The study subjects comprised 20 male postpubertal SpragueDawley rats (120 g to $130 \mathrm{~g}$ ). Rats were housed in a temperature- and light-controlled environment with easy access to water and rat pellets. All experimental procedures were approved by the Ethics Committee of the Faculty of Medicine, Celal Bayar University, Manisa, Turkey. The animals were randomly allocated into 2 groups containing 10 rats each. Surgical procedures were performed under general anesthesia administered by intramuscular injection of $50 \mathrm{mg} / \mathrm{kg}$ ketamine hydrochloride. The skin of the scrotal area was shaved and prepared with $10 \%$ povidone iodine solution. A left vertical scrotal incision was performed.

In group 1, the left testes were twisted $720^{\circ}$ in a counterclockwise direction and testes were sutured by $6 / 0$ vicryl sutures to the scrotum. Scrotal incision was closed with $4 / 0$ chromic catgut. One hour later, the tail veins of the anaesthetized rats were cannulated by 24 gauge branule, and perfusion $\mathrm{CT}$ was performed with an automatic injector for both testes. Each animal was placed at the centre of the CT scanner (Somatom Emotion; Siemens, Erlangen, Germany) and underwent unenhanced scout scanning through the testicle; this was done to select the appropriate level for the perfusion CT study. At the selected location of testes, CT scanning was performed beginning $3 \mathrm{sec}$ onds before the intravenous bolus injection of $0.15 \mathrm{~mL} / \mathrm{kg}$ of an iodinated contrast agent (CM; Imeron 300; lomeprol, Altana-Pharma, Melville, NY) and continued for $30 \mathrm{sec}-$ onds; 30 images of each section were acquired. All images were acquired by using a $120-k V p$ tube voltage and an 80-mA tube current.

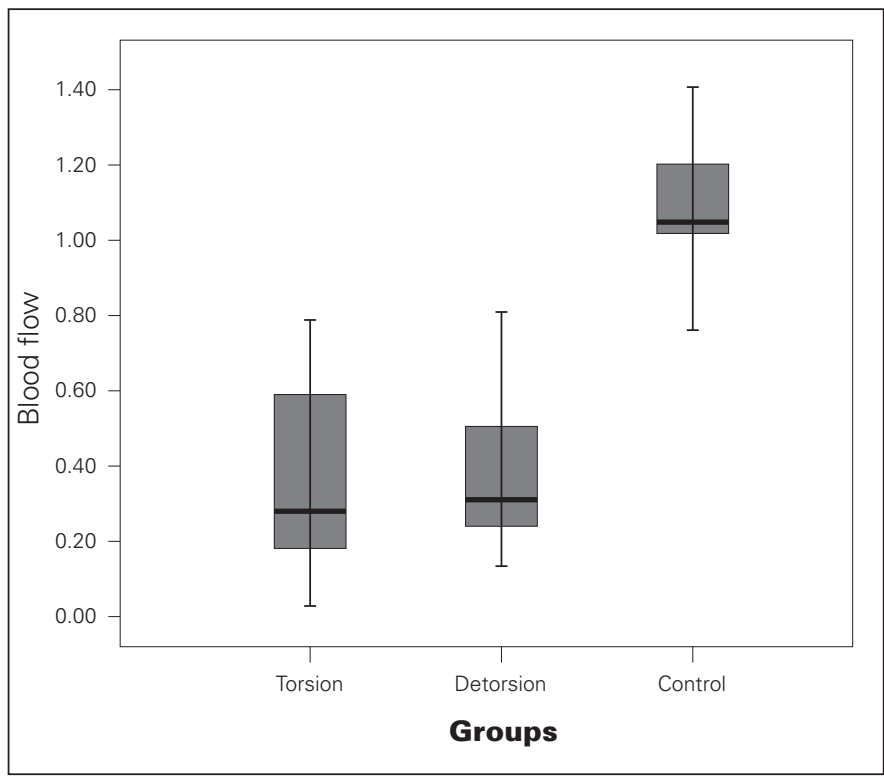

Fig. 1. The graphics showing the results of blood flow and groups.
Table 1. Johnson's scoring system

\begin{tabular}{cc}
\hline Level & Description \\
\hline 10 & Complete spermatogenesis and perfect tubules \\
\hline 9 & Many spermatozoa present but disorganized spermatogenesis \\
\hline 8 & Only a few spermatozoa present \\
\hline 7 & No spermatozoa but many spermatids present \\
\hline 6 & Only a few spermatids present \\
\hline 5 & No spermatozoa or spermatids present but many spermatocytes \\
\hline 4 & Only a few spermatocytes present \\
\hline 3 & Only spermatogonia present \\
\hline 2 & No germ cells present \\
\hline
\end{tabular}

The suture was removed after $\mathrm{CT}$ perfusion on the first hour of ischemia. The left testis was detwisted $720^{\circ}$ in clockwise direction and replaced in the scrotum for 2 hours of reperfusion. Perfusion CT was repeated to investigate testicular blood flow following reperfusion. The testes of Group 2 were explored through the vertical scrotal incision and skin was closed with $4 / 0$ chromic catgut. Perfusion CT was performed for Group 2 and was left as the Sham operated group. The animals were given a lethal dose of an anesthetic drug and both testes were excised for histopathologic examination. All testes were immersed in Bouin's fixative, harvested, embedded in parafin blocks, sectioned at $5 \mathrm{~mm}$ and stained with hematoxylin eosin. Johnson's score was used to evaluate spermatic activity (Table 1). ${ }^{7}$

The slice with the testicle's maximum extent was chosen and a region of interest (ROI) was placed on the tail's

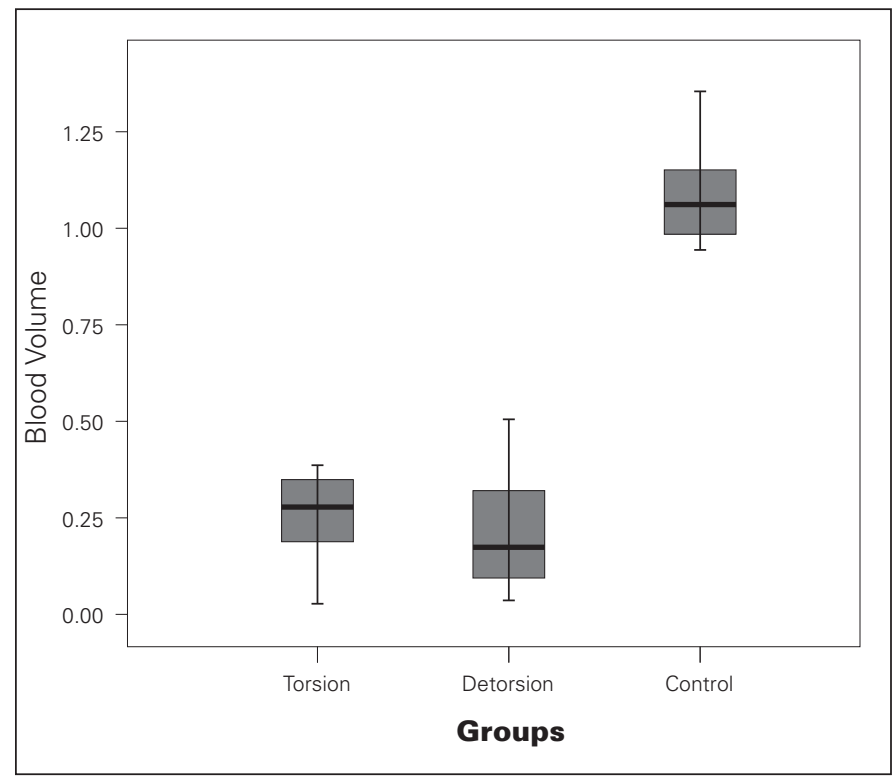

Fig. 2. The graphics showing the results of blood volume and groups. 
artery (caudal artery) for the evaluation of arterial input function and to optimize the density time curves. Coloured perfusion maps of this slice were obtained using standard perfusion software. On the coloured images a large ROI was manually placed including maximal testicular tissue (for the longer version of this article including the figures, please see the online version at www.cuaj.ca). The perfusion parameters of both torsioned, detortioned and contrlateral normal testicle were obtained in terms of BF, BV and time to peak (TTP) ratios.

The perfusion parameters we worked on are BV, BF and TTP values. Blood volume is the volume of the blood at the capillary-tissue level in terms of $\mathrm{mL}$ of blood/100 g tissue. It reflects the autoregulation mechanisms and capillary volume. Blood flow is the volume of blood per unit of time at the tissue level and is expressed in terms of $\mathrm{mL}$ blood/100 g tissue/min. Time to peak is the time between beginning of the contrast material administration and peak of the enhancement; TTP values are expressed in terms of second. Time to peak values are sensitive parameters but are usually affected by central hemodynamic changes. ${ }^{8}$

The software SPSS 14.0 for Windows (SPSS, Chicago, IL) was used for statistical evaluation. Differences among groups were statistically analyzed with Mann Whitney $U$ and Wilcoxon Signed Ranks.

\section{Results}

In this study, we used the ratio of BF, BV and TTP of the testicles (procedure applied/contrlateral normal) because these perfusion parameters can be affected by central hemodynamic changes. In this experimental model, we used arterial input function for optimizing the time-density curves and the ratio of the torsioned testicle and normal testicle to discharge these effects. The mean ratio of $\mathrm{BF}$ and $\mathrm{BV}$ of left testis to right testis were $0.37 \pm 0.28$ and $0.83 \pm 0.33$, respectively (Fig. 1, Fig. 2). The ratio of BF and BV values are significantly different between the torsion and control groups ( $p=0.01$ and $p=0.01$, respectively). There is no statistically significant correlation between the torsion and control groups' TTP values of the testes $(p=0.12$ and $p=0.90$, respectively). The normal testicular perfusion map in the control group, the BF perfusion maps of torsion and detorsion of the left testicle can be seen in the figures (for the longer version of this article including the figures, please see the online version at www.cuaj.ca).

There is no statistical difference between the torsion and detorsion groups' BF and BV ratio values $(p=0.86$ and $p=0.73$, respectively). There was no statistical difference between torsion and detorsion groups in terms of TTP ratio values ( $p=0.86$ and $p=0.61$, respectively).

Histopathological evaluation revealed hemorrhage under the tunica albuginea, peritesticular soft tissue and between the seminiferous tubules in the torsion group. No necrosis was seen. Spermatic activity of all seminiferous tubules was rated 10, according to Johnson's scoring system (Table 1). ${ }^{7}$

In the control group, congestion was observed in the vessels under tunica albuginea and peritesticular soft tissue. Hemorrhage was not seen. Spermatic activity of all seminiferous tubules was 10 according to Johnson's scale. ${ }^{7}$

\section{Discussion}

The most common causes of acute scrotum are appendix testis torsion, epididymitis, orchitis and testicular torsion. ${ }^{9}$ Differentiating between testicular torsion and epididimoorchitis is often difficult on physical examination, and some laboratory studies, such as testicular sonography with pulsed and colour Doppler examination and radionuclide scanning, are helpful in this regard. ${ }^{9,10}$

Doppler sonography enhances diagnosis by providing simultaneous real-time scrotal imaging with superimposed testicular BF information. ${ }^{11}$ But even though Doppler US is a very valuable diagnostic tool, the diagnosis cannot be confirmed in every case, as this method is highly dependent on the expertise and technique of the investigator. ${ }^{12}$ Inaccurate results may be obtained in the prepubertal patient with small testicular volume or in cases with multiple imaging and Doppler artifacts. Such imaging artifacts may result from inappropriate gain settings and the lack of slow-flow techniques. ${ }^{12,13}$ According to Kalfa and colleagues, ${ }^{14}$ colour Doppler US demonstrated $88.9 \%$ sensitivity, $98.8 \%$ specificity and $1 \%$ false positive results for testicular torsion. But Allen and Elder ${ }^{15}$ demonstrated 5 cases of testicular torsion in which findings on colour Doppler sonography were inconsistent with surgical findings. They described that colour Doppler sonography is helpful but should not be regarded as the definitive discriminator.

In cases with a clinically ambiguous picture or with indeterminate sonographic findings, scintigraphy is the viable imaging alternative and is used as an alternative to prevent false negative sonographic diagnosis. ${ }^{12}$ In 1983 Levy and colleagues ${ }^{16}$ defined the positive predictive value as $75 \%$ and the negative predictive value as $96 \%$, with a sensitivity of $90 \%$ and specificity of $89 \%$ for radionuclide scanning. When examining the acute scrotum, radionuclide imaging is more limited because it allows only an assessment of testicular blood flow. The false negative results are usually due to "the scrotal wall hyperemia." ${ }^{17}$ In addition, children with small scrotal sacs and testes that are not dependent may be difficult to assess with radionuclide imaging techniques.

Nussbaum Blask and colleagues ${ }^{18}$ and Paltiel and colleagues ${ }^{19}$ compared the 2 methods in different studies. Both studies showed that colour Doppler sonography and scintigraphy show similar sensitivity for the diagnosis of testicular torsion. They defined false-negative cases with either 
modality, and concluded that there is a need for complementary information in indeterminate cases.

Perfusion studies are obtained by analyzing the first pass of an iodinated contrast agent bolus through the vasculature. There is a linear relation between the contrast agent concentration and attenuation (density of the areas) because the contrast material used causes transient increase in the attenuation. The accuracy of functional CT perfusion measurements has been validated with the classic microsphere output technique, with positron emission tomography and with other modalities. Moreover, functional CT has been shown to be superior to conventional imaging in the early detection and differentiation of ischemic lesions because it enables the quantification of changes in tissue perfusion, which occurs earlier than structural changes do. ${ }^{20,21}$

According to our results, perfusion CT shows the insult in testicular perfusion in our experimental model of torsion. The systemic and metabolic factors that may affect the testicular blood circulation were eliminated by using the ratio of right and left testes. There was no difference in $\mathrm{BF}$ parameters between the torsion and detorsion groups. Perfusion CT may be considered insufficient to detect detorsion effects; however, we believe that the damage caused by an hour of $720^{\circ}$ torsion may not be maintained by reperfusion.

The main disadvantage of this method is the use of $\mathrm{x}$-rays. But as the alternative method to eliminate the false negative diagnosis of Doppler US is nuclear imaging, perfusion CT should be taken into consideration. Perfusion CT is a quantitative evaluation, and is not dependent on the expertise of the investigator. To avoid testicular loss or unnecessary surgery, an accurate diagnosis may be done by perfusion CT. Another disadvantage of this technique is the cost-effectiveness in comparison with Doppler sonography. However, perfusion CT is less expensive than radionuclide imaging. Moreover, the data obtained with CT perfusion may be used in similar perfusion studies performed with magnetic resonance imaging, which does not have the disadvantage of radiation exposure.

\section{Conclusion}

The purpose of our study was to determine the perfusion parameters measured with a functional CT and to examine the relationship between changes in perfusion and histologic parameters after torsion and detorsion. According to our results using our experimental model of torsion, perfusion may be considered an alternative method to diagnose testicular torsion in indeterminate cases.
*Celal Bayar University, Medical Faculty, Department of Radiology; ${ }^{\dagger}$ Department of Pediatric Surgery; §Department of Pathology, Manisa, Turkey

This paper has been peer-reviewed.

Competing interests: None declared.

\section{References}

1. Dogra V, Bhatt S. Acute painful scrotum. Radiol Clin North Am 2004;42:349-63.

2. Cummings JM, Boullier JA, Sekhon D, et al. Adult testicular torsion. J Urol 2002;167:2109-10.

3. Flanigan RC, DeKernion JB, Persky L. Acute scrotal pain and swelling in children: a surgical emergency. Urology 1981;17:51-3.

4. Gatti IM, Patrick Murphy J. Current management of the acute scrootum. Semin Pediatr Surg 2007;16: 58-63.

5. Miles KA, Charnsangavej C, Lee FT, et al. Application of $\mathrm{CT}$ in the investigation of angiogenesis in oncology. Acad Radiol 2000;7:840-50.

6. Kan Z, Phongkitkarun S, Kobayashi S, et al. Functional CT for quantifying tumor perfusion in antiangiogenic therapy in a rat model. Radiology 2005;237:151-8.

7. Johnson L, Petty CS, Neaves WB. The relationship of biopsy evaluations and testicular measurements to over-all daily sperm production in human testes. Fertil Steril 1980;34:36-40.

8. Cianfoni A, Colosimo C, Basile M, et al. Brain perfusion CT: principles, technique and clinical applications. Radiol Med 2007;112:1225-43.

9. Corbett HJ, Simpson ET. Management of the acute scrotum in children. ANZ J Surg 2002;72:226-8.

10. Schalamon J, Ainoedhofer H, Schleef J, et al. Management of acute scrotum in children —-the impact of Doppler ultrasound. J Pediatr Surg 2006;41:1377-80.

11. Hod N, Maizlin Z, Strauss S, et al. The relative merits of Doppler sonography in the evaluation of patients with clinically and scintigraphically suspected testicular torsion. Isr Med Assoc J 2004;6:13-5.

12. Albrecht T, Lotzof K, Hussain HK. Power Doppler US of the normal prepubertal testis: does it live up to its promises? Radiology 1997;203:227-31.

13. Atkinson Go, Patrick LE, Ball TI Jr. The normal and abnormal scrotum in children: evaluation with color Doppler sonography. Am J Roentgenol 1992;158:613-7.

14. Kalfa N, Veyrac C, Baud C, et al. Ultrasonography of the spermatic cord in children with testicular torsion: impact on the surgical strategy. J Urol 2004;172:1692-5.

15. Allen TD, Elder JS. Shortcomings of color Doppler sonography in the diagnosis of testicular torsion. J Urol 1995; 154:1508-10.

16. Levy OM, Gittelman MC, Strashun AM, et al. Diagnosis of acute testicular torsion using radiouclide scanning. J Urol 1983; 129:975-7.

17. Kogan $\mathrm{SJ}$, Lutzker $\mathrm{LG}$, Perez $\mathrm{LA}$, et al. The vale of the negative radionuclide scrotal scan in the management of the acutely inflamed scrotum in children. J Urol 1979;122:223-5.

18. Nussbaum Blask AR, Bulas D, Shalaby-Rana E, et al. Color Doppler sonography and scintigraphy of the testes: a prospective, comparative analyis in children with acute scrotal pain. Pediatr Emerg Care 2002;18:67-71.

19. Paltiel HJ, Connolly LP, Atala A, et al. Acute scrotal symptoms in boys with an indeterminate clinical presentation: comparison of color Doppler sonography and scintigraphy. Radiology 1998;207:223-31.

20. Miles KA, Griffiths MR. Perfusion CT: a worthwhile enhancement? Br I Radiol 2003;76:220-31.

21. Purdie TG, Henderson E, Lee TY. Functional CT imaging of antiangiogenesis in rabbit VX2 soft-tissue tumor. Phys Med Biol 2001;46:3161-75.

Correspondence: Dr. Omer Yilmaz, Celal Bayar University, Medical Faculty, Department of Pediatric Surgery, 45010, Manisa, Turkey; fax: +90 236 2370213; omeryilmaz71@gmail.com 